\title{
Keratinocyte growth factor is required for hair development but not for wound healing
}

\author{
Lifei Guo, Linda Degenstein, and Elaine Fuchs ${ }^{1}$ \\ Howard Hughes Medical Institute, Department of Molecular Genetics and Cell Biology, The University of Chicago, \\ Chicago, Illinois 60637 USA
}

\begin{abstract}
Keratinocyte growth factor (KGF), also known as fibroblast growth factor 7 (FGF7), is synthesized by skin fibroblasts. However, its mitogenic activity is on skin keratinocytes, where it is the most potent growth factor identified thus far. To explore KGF's function in vivo, we used embryonic stem cell technology to generate mice lacking KGF. Over time, their fur developed a matted appearance, very similar to that of the rough mouse, whose recessive mutation maps at or near the KGF locus on mouse chromosome 2 . In contrast to the recently reported transforming growth factor- $\alpha$ (TGF- $\alpha$ ) and FGF5 knockouts, which showed defects in the follicle outer-root sheath and the hair growth cycle, respectively, the hair defect in the KGF knockout seemed to be restricted to the cells giving rise to the hair shaft. Thus, we have uncovered a third, and at least partially nonoverlapping, growth factor pathway involved in orchestrating hair follicle growth and/or differentiation. Surprisingly, the absence of KGF resulted in no abnormalities in epidermal growth or wound healing. This was true even when we engineered double knockout mice, null for both KGF and TGF- $\alpha$, two factors that are increased dramatically in the normal wound-healing process. Whereas we found no evidence of compensatory changes at the mRNA level of wounded knockout mice, these data imply that the regulation of epidermal growth is complex and involves a number of growth stimulatory factors that go beyond what are thought to be the major paracrine and autocrine growth factors. We suggest that the redundancy in epidermal growth and wound healing is likely to stem from the vitality of these functions to the organism, a feature that is not a consideration for the hair follicle.
\end{abstract}

[Key Words: KGF; TGF- $\alpha$; epidermis; hair; gene knockout; wound healing]

Received August 25, 1995; revised version accepted November 15, 1995.

Two growth factors have surfaced as potent mitogens for cultured epidermal keratinocytes. Transforming growth factor- $\alpha$ (TGF- $\alpha$ ) is made by keratinocytes and is more potent than epidermal growth factor (EGF), which shares the same receptor (Barrandon and Green 1987). Keratinocyte growth factor (KGF), also known as fibroblast growth factor 7 (FGF7), is made by dermal fibroblasts and is a paracrine growth factor for epidermal keratinocytes (Finch et al. 1989; Rubin et al. 1989). Both KGF and acidic FGF (aFGF) share the same tyrosine kinase receptor, KGFR, an alternatively spliced variant of FGF receptor-2 (FGFR2) (Miki et al. 1991, 1992; Johnson and Williams 1993). The stimulating effects of KGF on DNA synthesis in cultured keratinocytes are $2-10 \times$ greater than those of any known epidermal mitogens, including TGF- $\alpha$, EGF, aFGF, and basic FGF (bFGF) (Finch et al. 1989; Rubin et al. 1989). Additionally, the level of KGF mRNA has been reported to increase by as much as $160 \times$ upon skin injury (Werner et al. 1992).
Both TGF- $\alpha$ and KGF stimulate basal epidermal DNA synthesis in vivo as they do in vitro. Newborn transgenic mice expressing about five to six times higher than endogenous TGF- $\alpha$ levels in their epidermal basal layer display a dramatically thickened epidermis with a significant increase in the number of DNA-synthesizing basal cells (Vassar and Fuchs 1991). Transgenic mice expressing KGF in an autocrine fashion, that is, in their basal epidermal layer, also exhibit a hyperthickened, hyperproliferating epidermis (Guo et al. 1993), consistent with its implicated role in re-epithelialization during wound healing (Werner et al. 1992, 1994). In both transgenics, mitotically active cells are confined to a single epidermal layer, but an increase is seen in the thickness of the spinous, granular, and stratum corneum layers.

Collectively, our TGF- $\alpha$ and KGF transgenic data (Vassar and Fuchs 1991; Guo et al. 1993) reveal two important findings: (1) Under normal circumstances, neither the EGF nor the KGF receptor are saturated by their endogenous growth factor ligands; and (2) a good correlation exists between the proliferative ability of basal keratinocytes and the thickness of the epidermis. Thus, if

${ }^{1}$ Corresponding author. 
TGF- $\alpha$ and KGF are the major factors that are key to controlling the balance between dividing and differentiating cells, then the loss of these factors through gene targeting would be expected to result in a concomitant reduction in proliferation and a thinning of the epidermis, unless other lesser growth stimulatory factors are up-regulated to compensate. This said, TGF- $\alpha$ knockouts show no marked changes in the epidermis (Luetteke et al. 1993, Mann et al. 1993!, and whereas recent EGF receptor knockouts display an effect, there is still significant epidermal growth and proliferation in the absence of this pathway (Mietlinen et al. 1995; Sibilia and Wagner 1995; Threadgill et al. 1995). This leaves KGF, the most potent of all KGFs, as a key candidate to at least partially sustain growth and differentiation in this tissue in the absence of TGF- $\alpha$. To test this hypothesis directly, and to assess whether KGF is essential for wound healing, we used embryonic stem (ES) cell technology to ablate the KGF gene in mice and to create double knockout mice missing TGF- $\alpha$ as well as KGF.

The proposed functions for KGF extend well beyond the skin. In situ hybridization studies have localized KGF and KGFR mRNAs to the mesenchymal and epithelial compartments, respectively, of many organs where mesenchymal-epithelial interactions are instrumental to organogenesis. These tissues include lung, mammary glands, kidney, and salivary glands in addition to skin (Mason et al. 1994; Finch et al. 1995). Transgenic mouse studies have shown that KGF can have a profound effect on hair follicle and salivary gland development (Guo et al. 1993; Pierce et al. 1994), and it can stimulate proliferation of type II pneumocytes in vivo as well as in vitro (Panos et al. 1993; Ulich et al. 1994). KGF has also been shown to stimulate proliferation in pancreatic ducts, mammary gland ducts, liver, and gastrointestinal epithelia (Housley et al. 1994; Ulich et al. 1994; Yi et al. 1994). Most recently, KGF has been found to mediate androgen action in androgen-dependent epithelia such as the prostate and seminal vesicles (Yan et al. 1992; Alarid et al. 1994). Thus, an initial concern in embarking upon a knockout approach for KGF is that it might cause embryonic lethality.

We report here the generation and analysis of KGF null mice and of KGF-TGF- $\alpha$ double knockout mice. Our study reveals a number of surprising and unexpected results.

\section{Results}

\section{Generation of KGF null mutant mice}

The human KGF cDNA has been cloned and characterized in its entirety (Finch et al. 1989). Its gene has also been partially characterized (Kelley et al. 1992) and maps to human chromosome 15 , which corresponds to the $F_{2}$ domain of the mouse chromosome 2 (Mattei et al. 1995; M. LeBeau, L. Guo, and E. Fuchs, unpubl.). Like the gene for other FGFs, the KGF gene consists of three exons, and sequences of exon 1 have been shown to be indispensable for KGF's association with heparin and for its subsequent binding to KGFR (Ron et al. 1993). The role of exon 1 in conferring receptor specificity to FGFs is in good agreement with the knowledge that exon 1 sequences are the least conserved of the three exons of FGF genes. With this in mind, we decided to target the disruption of exon 1 in the mouse KGF gene.

An isogenic Sv-129 mouse genomic library was screened with a human KGF cDNA probe corresponding to partial exon 1 sequences. One of the resulting clones, mKGF $\lambda 1$, was characterized further. Its restriction map is shown in Figure 1A (thin line). Regions of the presumed exon 1 were sequenced, revealing $100 \%$ identity with the known sequence of mouse KGF cDNA (kindly provided to us by Dr. Clive Dickson of the Imperial Cancer Research Fund, London, UK). Southern analysis using the exon 1 probe showed that there is only a single KGF gene in the mouse genome, consistent with a similar finding for human KGF (Kelley et al. 1992).

A targeting vector for the mKGF exon 1 was constructed from mKGF 1 genomic DNA (Fig. 1A, thick line). Two $\sim 3-k b$ mKGF genomic fragments were used as $5^{\prime}$ and $3^{\prime}$ arms. The vector was designed to eliminate a 205-bp fragment within exon 1, starting from a BamHI site just downstream of the ATG starting codon and ending at a KpnI site near the $3^{\prime}$ end of exon 1 . In its place, we put a $1.8 \mathrm{-kb}$ fragment containing a neomycin resistance gene under the control of the phosphoglycerate kinase (pgk1) promoter. The $5^{\prime}$ arm of the vector was flanked externally by the pgk1-herpes thymidine kinase gene, used for negative selection.

The targeting vector DNA was transfected into R1 ES cells, and the transfectants were subjected to positive (G418) and negative (Gancyclovir) selection. DNAs from surviving colonies were isolated and screened for the desired homologous recombinations. PCR was used to identify candidates for homologous recombination, and these were then confirmed by Southern blot analysis (not shown). Of a total of 70 ES clones analyzed, 2 scored positive for homologous recombination and displayed identical hybridization patterns.

The two mutant clones were injected separately into C57BL/ 6 blastocysts to produce high-percentage chimeric animals, which were mated with $\mathrm{C} 57 \mathrm{BL} / 6 \mathrm{fe}-$ males. Heterozygous offspring were then mated to produce homozygous mutants, which occurred at the expected Mendelian frequency. The offspring were tested for the mKGF mutation by Southern blot analysis (Fig. 1B).

To assess whether the targeted homologous recombination resulted in ablation of KGF mRNA, reverse transcriptase (RT)-PCR analysis was conducted on RNAs extracted from tissues of $(+1+1,1+1-1$, and $1-1-1$ mice. Whereas the reactions produced a KGF-specific band of the expected size in the $(+1+)$ and $(+1-)$ RNA samples, no band was seen in the $(-/-)$ RNA samples (Fig. 1C). Confirmatory data were provided by Northern blot analysis and RNase protection assays of the skin RNA samples. All data were consistent and verified that the mu- 


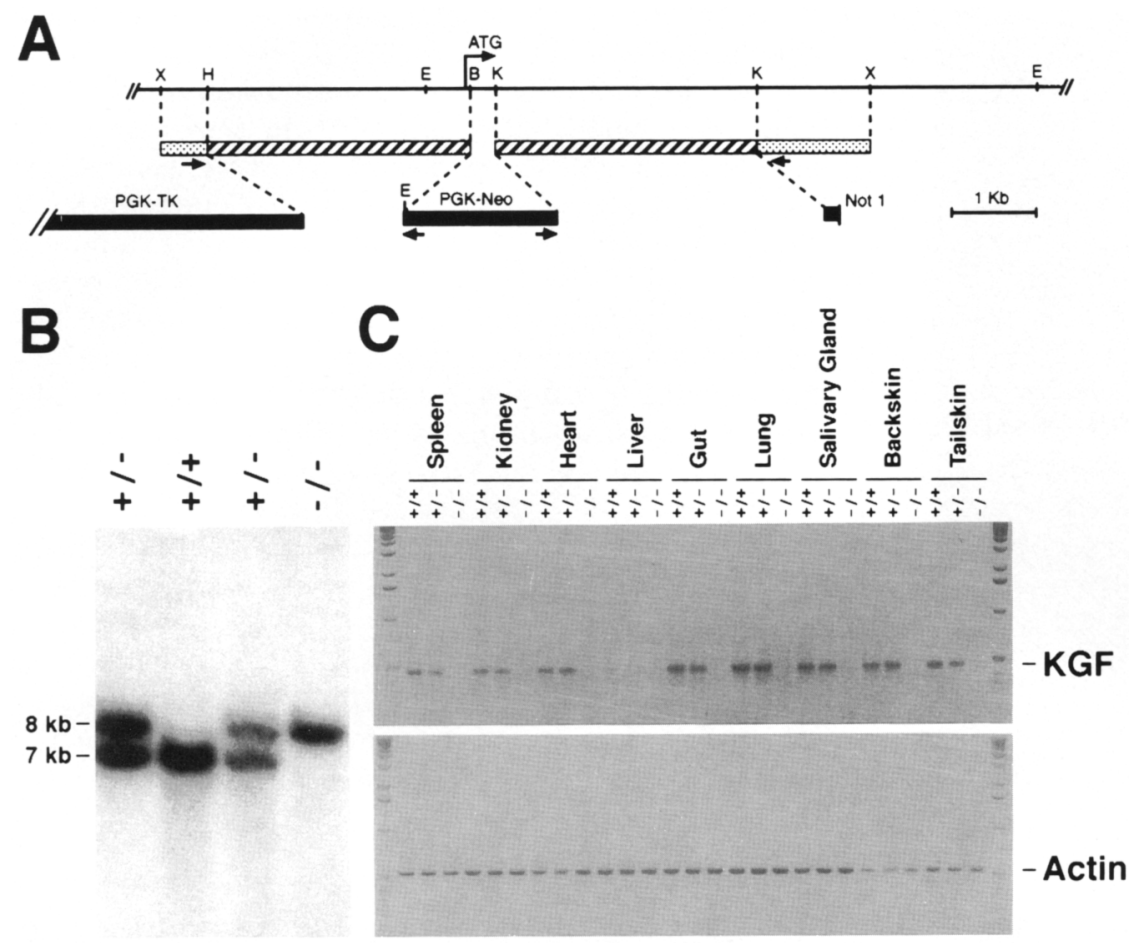
The 475-bp KGF-specific fragment was detected in RNAs from $(+1+)$ and $1+1-\mid$ mice, but not in RNAs from $(-1-)$ mice. All RNAs produced a 525-bp actin-specific fragment, generated as a control.

tation in the KGF gene compromised the mouse's ability to produce a stable KGF RNA.

\section{The KGF null mice resemble rough mutant mice}

As newborns, KGF null mice displayed no obvious abnormalities. However, by $\sim 2$ months of age, homozygous mutant mice became distinguishable from control mice (Fig. 2A). Most notable was the hair coat, which developed a somewhat greasy or matted appearance, a phenomenon that was particularly conspicuous among the male mutant mice. However, no oil or greasy substances were detected upon blotting the hairs. The rough nature of the hair coat became more prominent with age (Fig. 2B; same animals as shown in 2A, but at 11 months of age). By 1 year, females also displayed this phenotype (not shown).

Surprisingly, despite obvious visual differences in hair coat, no major abnormalities were detected on the surface of the hairs when visualized by scanning electron microscopy (Fig. 3A,B) or light microscopy (Fig. 3C-F). Moreover, the relative populations of different hair types remained unaffected in the KGF-null mice: In a group of 100 hairs examined from 2-month-old control and KGF null animals, the relative percentage of awl/auchene to zigzag hairs was $21 \%: 79 \%$ in the control and $23 \%: 77 \%$ in the KGF null mouse. In two 12-month-old control animals, the percentage of awl/auchene to zigzag hairs was $27 \%: 73 \%$ and $25 \%: 75 \%$, with $>1000$ hairs counted.

Figure 1. KGF targeting vector, identification of homologous recombinants in mice, and analysis of KGF mRNA expression in $1+1+1,1+1-1$ and $(-1-)$ tissues. (A) Schematic representation of the mouse KGF allele (thin line) and targeting vector (solid bars). The KGF translation initiation site is denoted by a bent arrow. Just $3^{\prime}$ to this is the 205-bp BamHI-KpnI fragment, encompassing most of exon 1 , which was replaced with a neomycin gene driven by a phosphoglycerate kinase (PGK) promoter. Short arrows denote primers used initially to screen for homologous recombination. Hatched boxes represent $5^{\prime}$ and $3^{\prime}$ homologous arms; stippled boxes represent the $5^{\prime}$ and $3^{\prime}$ fragments used for probing Southern blots. (PGK-TK) The herpes thymidine kinase gene driven by a PGK promoter and used for negative selection; $(\mathrm{X})$ $X b a I$; (H) HindIII; (E) EcoRI; (B) BamHI; (K) KpnI. $(B)$ Southern blot confirmation of EcoRI-digested, mouse tail DNAs $\{10 \mu \mathrm{g}$ each) from wild type $(+1+1$, heterozygous $(+/-)$, and homozygous $(-1-)$ KGF-null mutant mice. The blot was hybridized with radiolabeled probe to the $3^{\prime} \mathrm{KpnI}-$ $X b a I$ fragment. Expected bands: $(7 \mathrm{~kb})$
As in $(-/-)$ tissues known to express KGF.

(n)

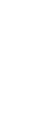



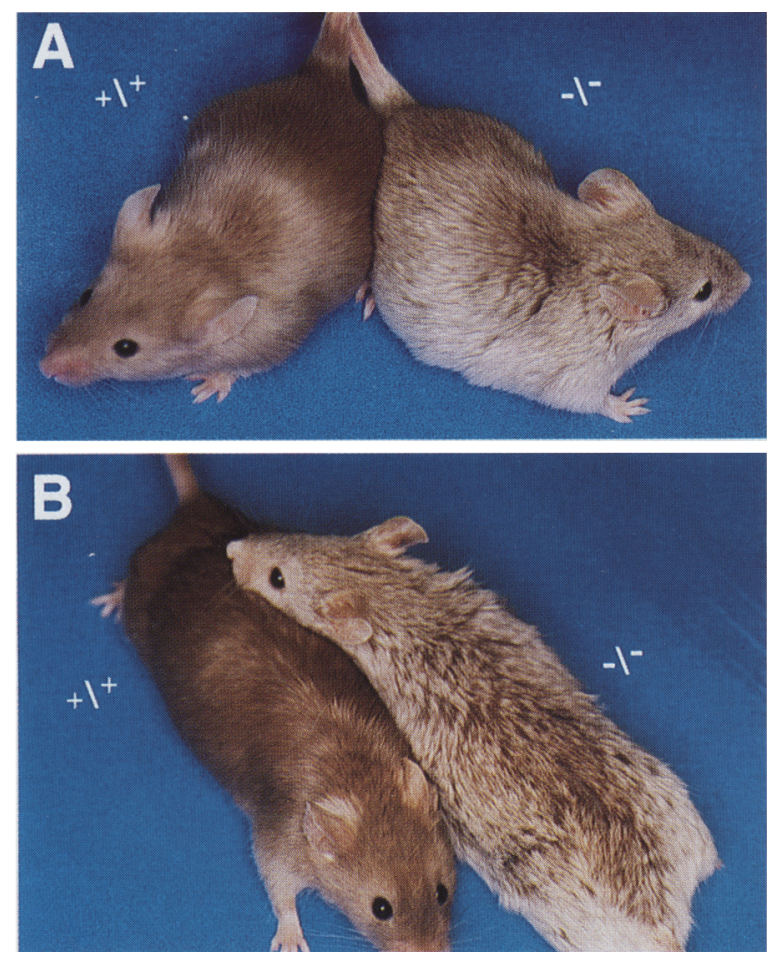

Figure 2. Phenotype of KGF null mice. A matched pair of KGF $(+1+)$ and $(-1-)$ male mice were photographed at 2 months of age $(A)$ and 1 year of age $(B)$. Note the rough and unkempt appearance of the KGF $(-1-)$ male mouse relative to the control male $1+1+1$. As seen in the photos, this phenotype became more pronounced with age, appearing earliest in young adult males but later in females as well.

morphology of the testes and seminal vesicles or the histology of these tissues (not shown). These data are consistent with those obtained for the testicular feminization mutant mouse, which displays a normal hair coat despite the presence of a defective androgen receptor (Lyon and Hawkes 1972). Thus, the aberrations in hair coat cannot be attributed to indirect effects involving androgen receptor responses.

Previous knockouts of TGF- $\alpha$ (Luetteke et al. 1993; Mann et al. 1993) and FGF5 (Hebert et al. 1994) have also produced abnormalities in the hair coat of null mice. In TGF- $\alpha$ null mice, defects in the hair shaft arose from structural aberrations in the outer root sheath (ORS) and/or inner root sheath (IRS) of the follicles. In FGF5 knockout mice, defects were in the lengths of hairs, and this stemmed from a lengthening of the anagen phase of the hair cycle. In contrast to TGF- $\alpha$ knockout mice, the morphology of hair follicles in KGF knockout mice was indistinguishable from control follicles (Fig. 3G,H). In contrast to FGF5 knockout mice, hair lengths were unchanged (most easily measured by the lengths of awl hairs: control, $9.5 \pm 1.1 \mathrm{~mm}$; KGF null, $9.5 \pm 1.3 \mathrm{~mm}$ ). Thus, whereas all three growth factor knockout mice displayed aberrations in hair coat, the defects were clearly distinct, implying the existence of at least three nonredundant growth factor pathways in hair follicle growth and/or differentiation.

Whereas our KGF null mice were markedly different from TGF- $\alpha$ and FGF5 knockout mice, they bore a pronounced resemblance to the recessive mouse mutant rough (ro) described $>40$ years ago (Falconer and Snell 1953). Originating from a random mutation in a mouse colony, ro was distinguished on the basis of the greasy and rough appearance of the hair coat. Whereas very little is known about this mutant, ro is closely linked to a genetic marker that has recently been mapped to the $F_{2}$ domain of mouse chromosome 2 (Siracusa and Abbott 1994). Intriguingly, this locus is at or near the KGF locus (Mattei et al. 1995; M. LeBeau, L. Guo, and E. Fuchs, unpubl.). One other characteristic attributed to ro mice is that they have slightly curled whiskers when they are young, a trait that disappears as the mice grow older. Whereas we did not observe this feature in our KGF null mice, this could be attributable to background variations between the Sv-129 strain used for ES technology and the
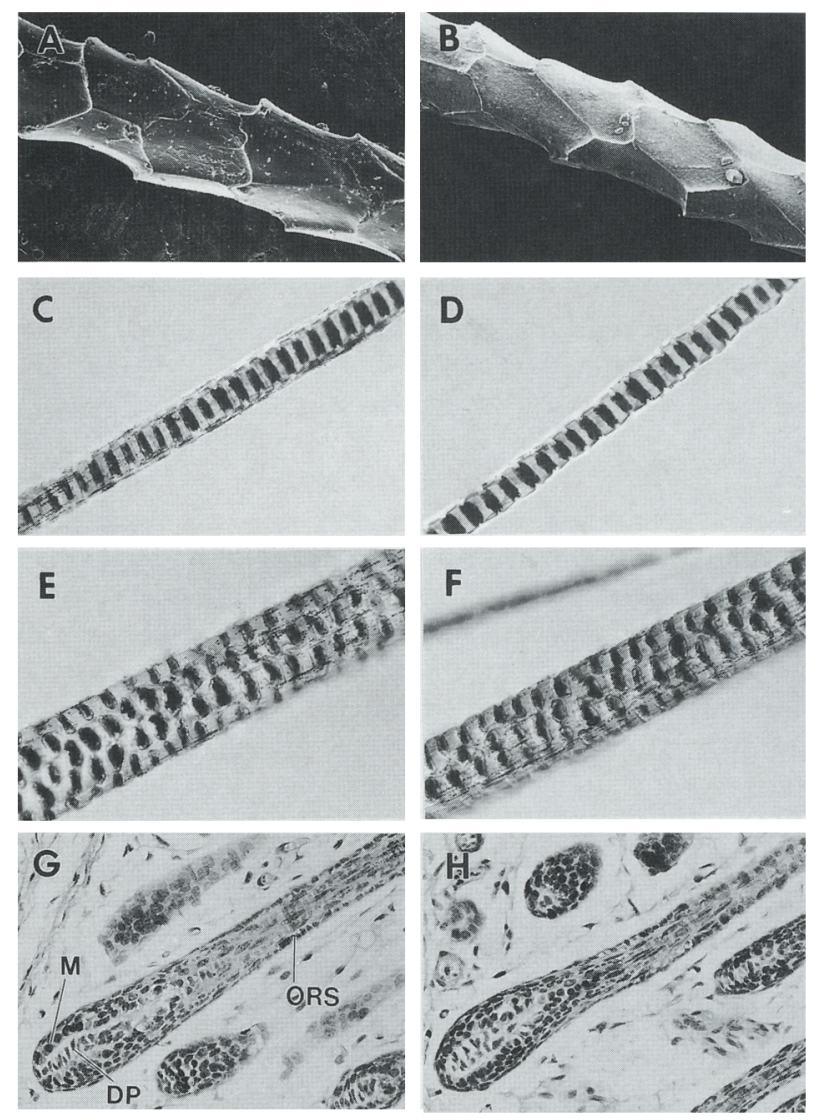

Figure 3. Analysis of hairs of KGF null mice. Scanning electron microscopy $(1200 \times)$ analysis was conducted to show the surface of $a w l$ hairs of control $(A)$ and KGF null mice $(B)$. Light microscopy $(\sim 1500 \times)$ was also used to show the inner structures of zigzag $(C, D)$ and $a w l(E, F)$ hairs of control $(C, E)$ and KGF null mice $(D, F) .(G-H)$ Hematoxylin- and eosin-stained skin sections of control $(G)$ and KGF-null $(H)$ mouse (63× objective). Note normal morphology of hair follicles in KGF null mouse. 
RIII strain in which the original ro mutant was described.

\section{$K G F$ is not required for the development of many mesenchymal epithelial organs}

Whereas the ablation of KGF resulted in clear aberrations in hair coat, it produced no obvious consequences to other tissues known to respond to KGF. Thus, as judged by histological analysis of tissue sections, the epidermis of backskin showed no changes in thickness or morphology either in newborn or adult KGF null animals (Fig. 4). Similarly, all other stratified squamous epithelia, including tongue, ear, and forestomach, appeared indistinguishable from their control counterparts (Fig. 5). We also examined sections of other tissues where mesenchymal-epithelial interactions are important and where KGF is known to be expressed. All of these tissues appeared normal, including salivary glands, kidney, lung, spleen, liver, small intestine, and heart (data not shown). Finally, both male and female KGF $(-/-)$ mice were normal in their fertility and sexual behavior, suggesting that their reproductive organs were fully functional. Even at the ultrastructural level, we failed to detect any marked differences. Thus, despite the broad range of ep-
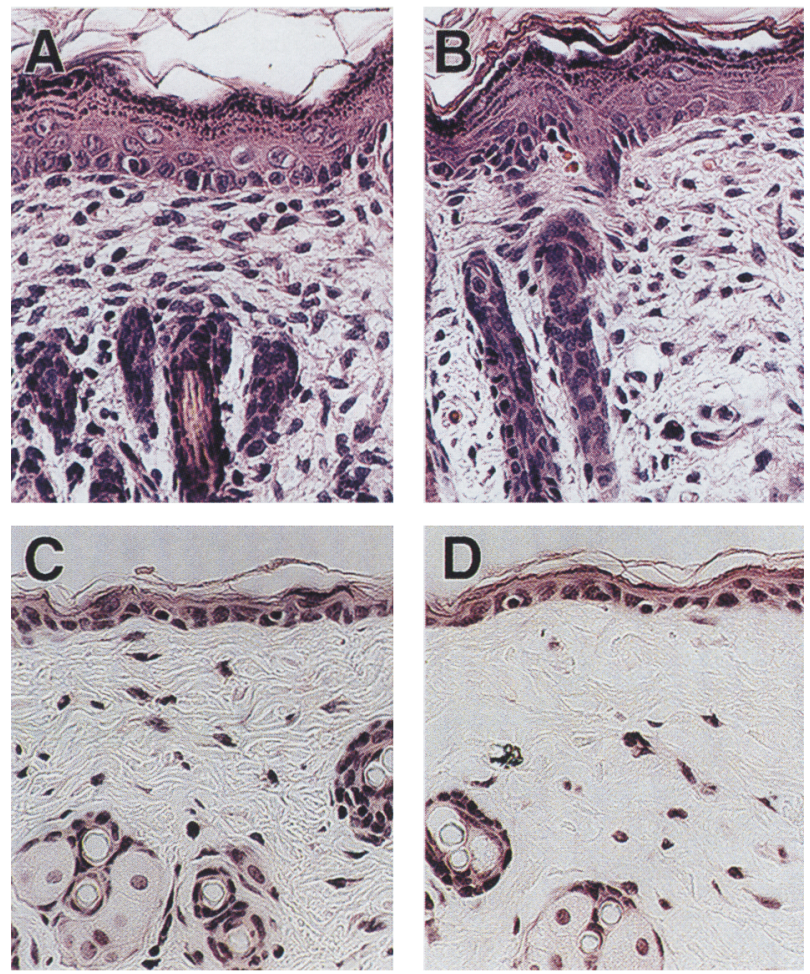

Figure 4. Analysis of epidermis of KGF null mice. Hematoxylin-and eosin-stained backskin sections from control $(A, C)$ and $\mathrm{KGF}(-/-)(B, D)$ mice; all frames were taken at the same magnification $(40 \times$ objective). $(A, B)$ Newborn mice; $(C, D)$ adult mice. Note normal morphology of epidermis in KGF null mouse.
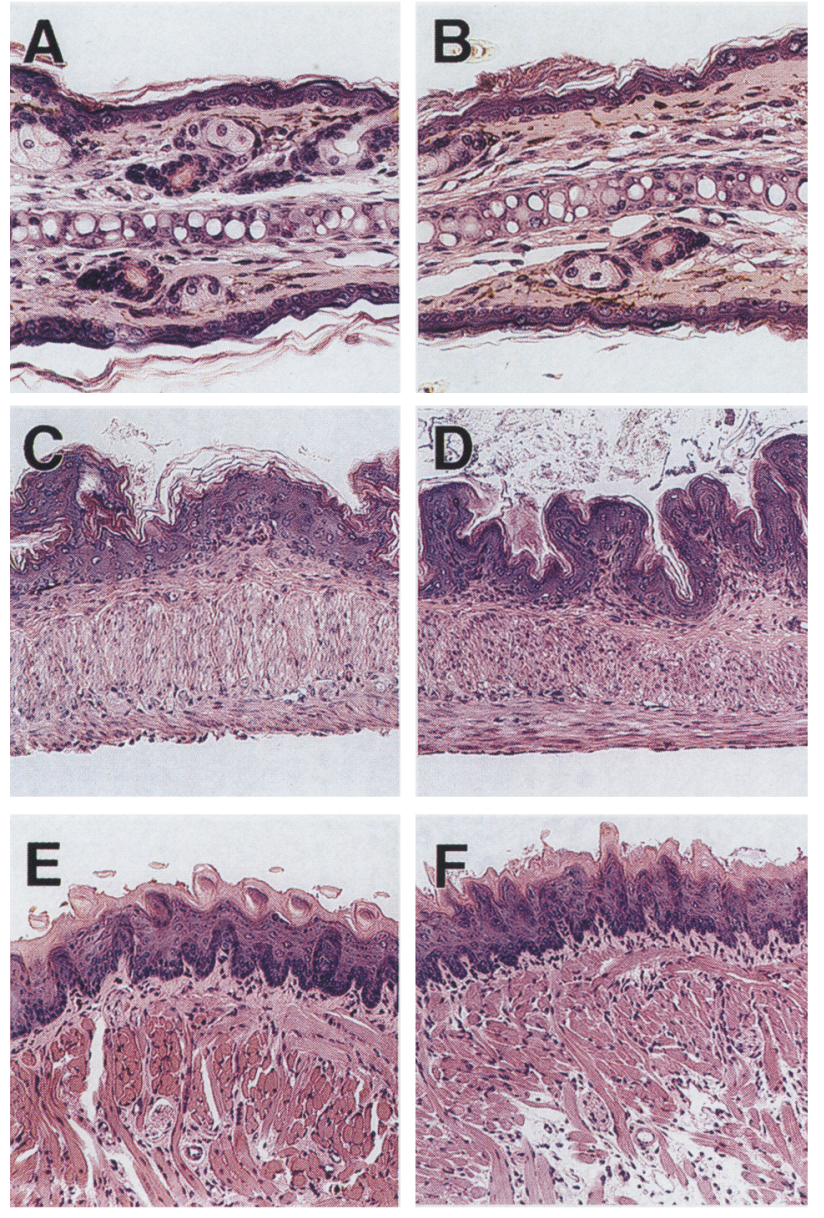

Figure 5. Comparison of histology of other stratified squamous epithelia. (Left panels) From control $(+/+)$ mice; (right panels) from KGF $(-1-)$ mice $(40 \times$ objective $)$. Hematoxylinand eosin-stained sections are from ear skin $(A-B)$; forestomach $|C-D|$; and tongue $(E-F)$.

ithelial cells known to be targets for KGF, this growth factor is apparently dispensable for most aspects of tissue development.

\section{KGF is not required for wound healing}

Given recent reports that KGF mRNA levels are elevated dramatically during wound healing (Werner et al. 1992), we were particularly interested to examine whether the KGF null mice would be able to function properly in response to skin injury. To this end, a wound-healing experiment was conducted on age- and sex-matched KGF $(+1+)$ and $(-1-)$ mice. Full thickness incisions were made on the back of both the control and KGF null mice, and wound sites were examined 1, 3, 5, and 7 days after the original wounding. Much to our surprise, the wounds healed as quickly in KGF null mice as in control mice. When the corresponding backskin tissues were analyzed histologically, no apparent irregularities were detected in the epidermis or in the dermis of the reepithelializing 
skin (Fig. 6). Additionally, in vivo labeling with BrdU revealed comparable percentages of DNA-synthesizing epidermal cells in $(+/+)$ and $(-/-)$ skins, irrespective of age (data not shown). Wounding by tail amputation was also conducted, and again, the healing process was indistinguishable between the control and KGF null mice. In a total of five separate wound-healing experiments, keratinocyte proliferation and migration proceeded normally in KGF null mice. These data demonstrate unequivocally that KGF is dispensable for the wound-healing process, in contrast to previous assumptions (see, e.g., Werner et al. 1994).

\section{mRNAs encoding other major growth factors are not up-regulated in KGF null mice}

KGFR binds both KGF and aFGF with high affinity, although aFGF is considerably less potent than KGF as a mitogen for keratinocytes (Rubin et al. 1989). Previous reports have suggested that aFGF RNAs are also amplified during normal wound healing, albeit to a lesser extent than KGF RNAs (Werner et al. 1994). Given that the levels of KGF and aFGF mRNAs can change markedly during wound healing, we wondered whether this level of regulation might also be triggered under conditions where KGF activity has been ablated. Therefore, we tested the possibility that aFGF RNA levels /or the levels of other growth factor RNAs) might rise to compensate for the loss of KGF in our knockout mice. To this end, RNase protection assays were conducted on $(+1+)$ and $(-1-\mid$ RNAs isolated from wounded and unwounded skin (see Materials and methods).

As shown in Figure 7, the base level of KGF RNAs in wild-type Sv-129 mice was higher than described previously for BALB/c animals (Werner et al. 1992). Nevertheless, consistent with this previous report, KGF RNA levels in control mice rose markedly in response to skin injury. aFGF RNA levels were also elevated significantly during the wound-healing process (Fig. 7). However, the degree to which aFGF mRNAs increased in wound healing was comparable in both $(+1+)$ and $(-1-)$ animals. This was also true for the mRNAs encoding TGF- $\alpha$, EGF, and bFGF, which are all known to play a role in epidermal growth (Rheinwald and Green 1975; Barrandon and Green 1987; Schultz et al. 1987; Rappolee et al. 1988; Rubin et al. 1989; Mann et al. 1993). Thus, at least at the RNA level, no compensatory relationship was detected between KGF and other known stimulatory factors for epidermal growth.

A surprising finding of our analyses was the dramatic increase seen in TGF- $\alpha$ RNA levels upon wounding (Fig. 7). Whereas increases in aFGF and KGF mRNAs were expected during re-epithelialization of skin injuries (Werner et al. 1992), changes in TGF- $\alpha$ message were even more striking than the FGF message changes. These results were consistent with those obtained from Northern blot analysis of mRNA samples collected in a separate experiment (data not shown). Taken together, these data show that despite the existence of regulatory mechanisms that can substantially alter the levels of growth factor mRNAs during wound healing, these mechanisms do not appear to be perturbed as a consequence of the ablation of the KGF gene in mice. Whether compensation exists at the post-translational level is a significantly more challenging issue that remains to be explored.

\section{Ablation of KGF and TGF- $\alpha$ in double knockout mice reveals no new abnormalities not seen in single knockout mice}

TGF- $\alpha$-null mice have a defective ORS and altered hair
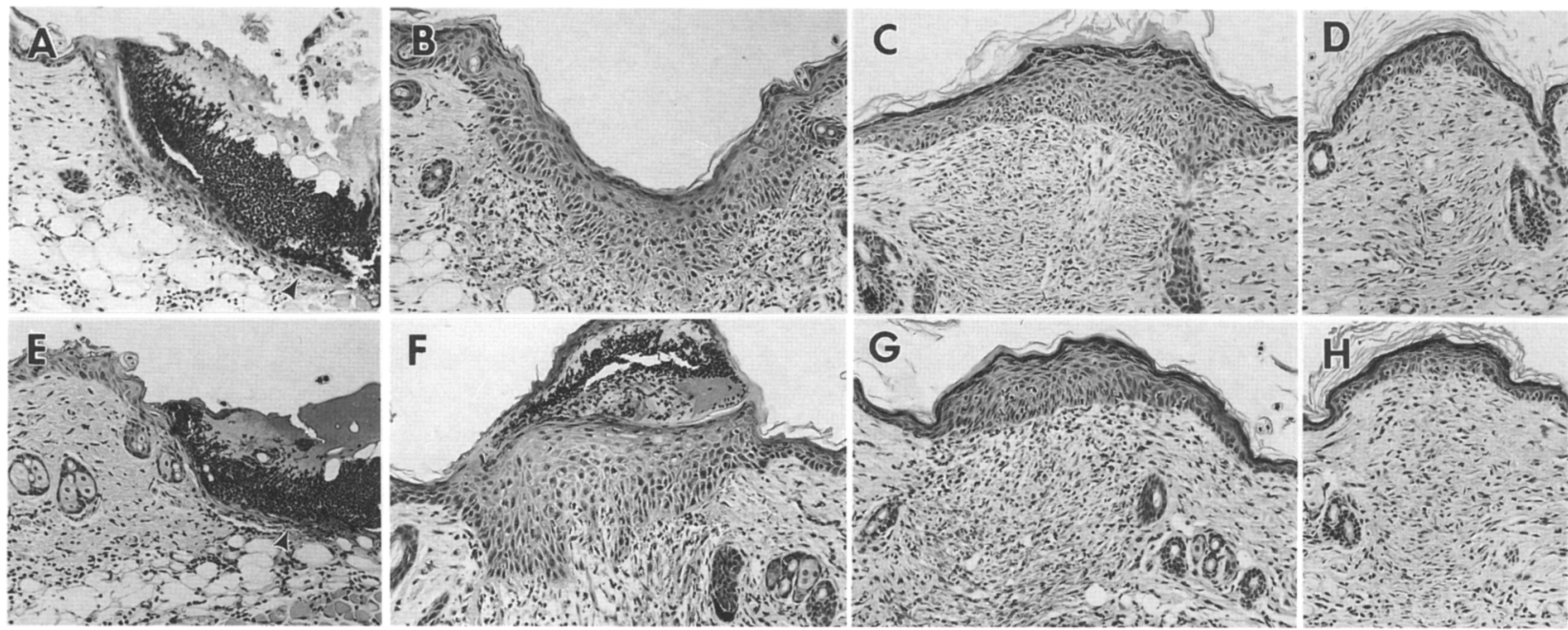

Figure 6. The wound-healing process is normal in KGF null mice. The backs of anesthetized mice were subjected to superficial skin injury by scalpel incisions (see Materials and methods). Skin tissues within $2 \mathrm{~mm}$ of the wound sites were then excised, fixed, sectioned, and stained at 1 day $(A, E), 3$ days $(B, F), 5$ days $(C, G)$, and 7 days $(D, H)$ after wounding. (Top panels) Control mice; (bottom panels) KGF null mice. Arrowheads in $A$ and $E$ indicate migration positions reached by the keratinocytes undergoing reepithelialization. All frames were taken at the same magnification $(20 \times$ objective). 


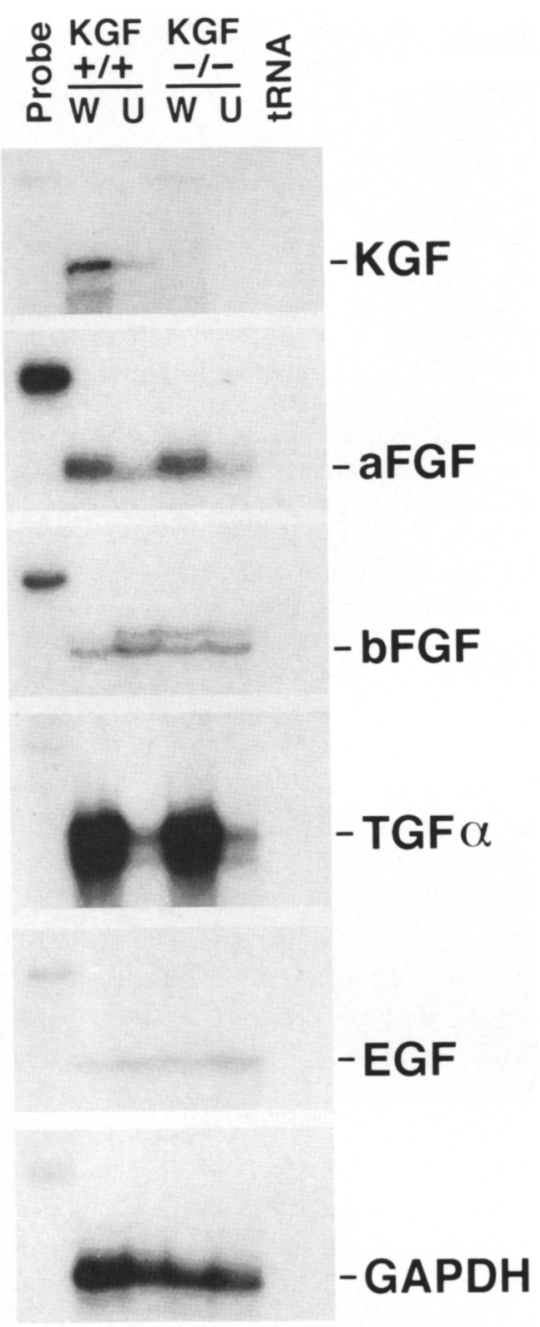

Figure 7. Levels of RNAs encoding other growth factors are unaffected in KGF knockout mice even during wound healing. RNase protection assays were conducted to measure the levels of growth factor RNAs in wounded $(W)$ and unwounded $(U)$ skin. Skin RNAs were isolated and incubated with RT-PCRgenerated radiolabeled cRNAs corresponding to a number of different growth factor sequences. Following RNase treatment, protected fragments were resolved by gel electrophoresis as described in Materials and methods. Expected bands are KGF 1574 bp), aFGF (423 bp), bFGF (351 bp), TGF- $\alpha$ (413 bp), EGF (568 bp), and glyceraldehyde phosphate dehydrogenase (GAPDH; $250 \mathrm{bp}$ ). The first lane of each assay represents free probe corresponding to the appropriate cRNA; the next four lanes represent skin RNA fragments protected from RNase digestion by hybridization with the cRNA; the last lane represents a yeast tRNA control, following hybridization with the cRNA and digestion with RNase. The particular cRNA probe used in each assay is indicated at right.

follicle structure, but their epidermis is of normal thickness and it behaves normally during wound healing (Luetteke et al. 1993; Mann et al. 1993). To address the possibility that the major autocrine and paracrine growth factors may have partially overlapping and compensatory functions, we engineered double knockout mice by mating the TGF- $\alpha(-/-)$ mice (Mann et al. 1993) with our KGF (-/ - ) mice. Double knockout mice displayed a wavy and rough hair coat, with hairs curving upward in an unkempt manner. These findings are consistent with a linear addition of the two individual phenotypes (not shown). Further analysis of hair follicle defects revealed no new abnormalities that were not detected in either of the single knockout mice. Newborn TGF- $\alpha$ null epidermis seemed to be somewhat thinner than that of control animals. This was not seen in the KGF null mice but was observed in the double knockout mice (not shown). Thus, with respect to epidermal and hair follicle development and differentiation, the effects of KGF and TGF- $\alpha$ appear to be nonoverlapping.

Similar histological analysis of the epidermis also revealed no major differences between the single and double knockout mice (not shown). Furthermore, when these animals were subjected to wounding, no irregularities were detected in the re-epithelialization process (Fig. 8: (A) control; (B) KGF single knockout; (C) KGFTGF- $\alpha$ double knockout). Thus, even when expression of TGF- $\alpha$ was also ablated, the loss of KGF had no effect on the wound-healing process. Conversely, despite its remarkable up-regulation in response to injury, TGF- $\alpha$ was not required for wound healing, even in the absence of KGF.

\section{Discussion \\ Unique functions of $K G F$}

Our study of the KGF knockout mice pointed to one feature, namely a smooth and healthy hair coat, which required KGF and which was not compensated for by other factors. The similarity between our KGF knockout mice and the ro mutant described previously (Falconer and Snell 1953) suggests that a naturally occurring KGF null mutation was isolated $>40$ years ago. The rough and somewhat greasy appearance of the hair coat first became prominent in adult KGF $1-/-1$ males. In rats, the fur coat of adult males is naturally coarser than that of females (Mohn 1958). Because similar features seemed to be accentuated in our KGF $(-1-)$ male mice, because seminal vesicle branching morphogenesis can be inhibited by anti-KGF in organ culture (Alarid et al. 1994), and because KGF-mediated changes in prostate gene expression seem to require androgen response elements (Culig et al. 1994), it seemed likely that the processes that are altered in the KGF knockout mice might be influenced or mediated by androgens. However, we did not detect aberrations in either the morphology or histology of the male reproductive system or in the ability of our KGF $|-/-|$ males to produce viable sperm. Most compelling is the fact that mutant mice defective in their androgen receptor exhibit no discernible abnormalities in their hair coat (Lyon and Hawkes 1972). The fact that females do develop the phenotype, albeit later in age, lends further support to the notion that the hair-related defects in KGF null mice are direct rather than indirect.

The unique functions of KGF were clearly distinct and 

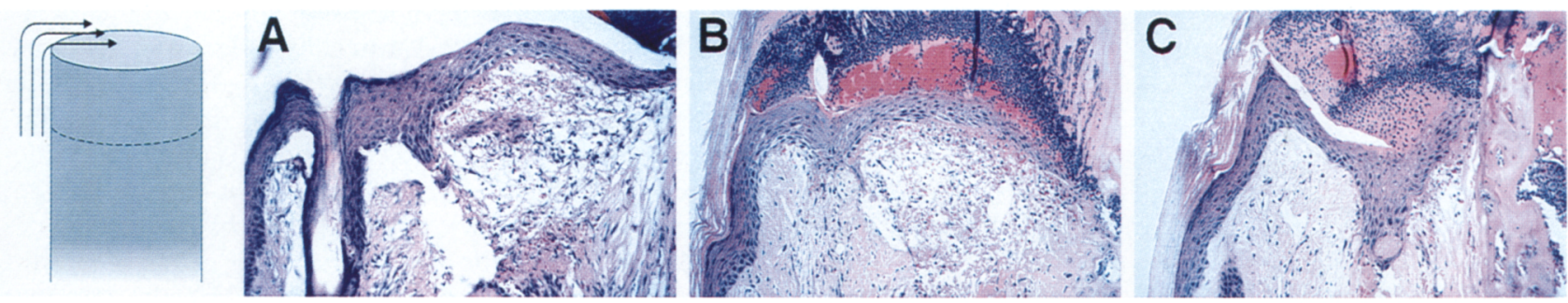

Figure 8. Reepithelialization of wounds is normal in KGF-TGF- $\alpha$ double knockout mice. Wounding was accomplished by tail segment amputations, and BrdU was injected just prior to harvesting samples, as described in Materials and methods. Shown are hematoxylin- and eosin-stained skin sections from the exposed portion of the remaining tail at 3 days after the initial wound. All sections were photographed at the same magnification (20x objective), and photos were oriented as indicated in the schematic diagram of an amputated tail segment (left). Arrows indicate the direction of the re-epithelialization process. $(A) \mathrm{Control} ;(B) \mathrm{KGF}$ single knockout; $(C)$ KGF-TGF- $\alpha$ double knockout. Note: By day 1, BrdU labeling was markedly elevated (not shown), and keratinocytes had begun to migrate. By day 3 (shown), keratinocytes had migrated more than half the distance between the wound edge and the protruding bone. By day 5 (not shown), cells had covered the wound. Note also that the re-epithelialization of backskin wounds (see Fig. 6) proceeded more rapidly than tail wounds, presumably because of the higher density of backskin hair follicles, known to participate in wound healing.

did not overlap with the unique functions of TGF- $\alpha$. Like the TGF- $\alpha$ knockouts (Luetteke et al. 1993; Mann et al. 1993), the KGF knockout mice displayed significant aberrations in hair coat but not in epidermal morphology. However, the effects of TGF- $\alpha$ ablation were manifested most prominently in the distortion of the ORS and possibly the IRS, thereby leading to hair waviness. In contrast, whereas the effects of KGF ablation caused a rough and somewhat matted appearance of the fur coat, this did not arise from morphological abnormalities in the overall structure of the ORS, the IRS, or the hair follicle. The distinction in the types of hair defects arising from TGF$\alpha(-/-)$ versus $\mathrm{KGF}(-/-)$ knockout mice was perhaps most obvious in the double knockout, which displayed skin that appeared to be a linear addition of the individual knockouts. These differences suggest that if KGF has a function in the ORS or IRS, this function is either subtle or one that can be compensated for by other factors in the double knockout mice.

What then is the defect in the skin of our KGF null mice? Our results imply that the unique functions of KGF are on the matrix cells of the follicle, because these are the cells that subsequently give rise to the hair shaft. Although other possibilities exist, the simplest explanation is that KGFRs are present on matrix cells, whereas EGF receptors (EGFRs) are present on the ORS and/or IRS. In this regard, it is most interesting that Rosenquist and Martin (1996) have recently localized KGF mRNAs to the dermal papilla of the hair follicle, whereas KGF mRNA levels were below the limits of detection elsewhere in the skin. KGF RNAs seemed especially abundant in early anagen, but waned in late anagen, and were absent in catagen and telogen (Rosenquist and Martin 1996). These findings suggest a possible role for KGF in the hair cycle. The age-dependent appearance of the rough, unkempt hair coat would argue that if KGF ablation affects the hair cycle, then the perturbation must increase with the number of cycles a follicle has undergone. Additionally, because hair length did not seem markedly affected in KGF null mice, the defect seems more likely to be on differentiation rather than proliferation per se. Further studies will be necessary to assess the extent to which these predictions are correct.

It is worth noting that the phenotype of the KGF knockout mice is also clearly distinct from that described recently for the FGF5 knockout mice. Thus, ablation of the FGF5 gene led to the generation of another line of angora $(\mathrm{go} / \mathrm{go})$, a mutant mouse strain typified by unusually long hairs (Hebert et al. 1994). Analysis of go/ go revealed that FGF5 is expressed in the ORS of the hair follicle and functions as an inhibitor of hair growth, presumably through FGF receptors on either the matrix cells or the dermal papilla of the follicle (Hebert et al. 1994). In the case of FGF5 knockout mice, and in striking contrast to our FGF7 (KGF) knockout mice, hair length was increased markedly. Thus, in three different knockouts that all give rise to hair defects, the consequences are remarkably distinct and, in each case, at least partially nonoverlapping. These findings underscore the existence of at least three distinct growth factor pathways in hair differentiation and development.

The major paracrine and autocrine growth factors of the epidermis and its appendages are dispensable in wound healing and in keratinocyte growth in vivo

Wounding elicits a complex series of biological responses that are involved in the healing process. These responses include cell migration, proliferation, differentiation, removal of damaged tissue, and production of extracellular matrices (for review, see Clark 1985). The treatment of wounds with local applications of plateletderived growth factor (PDGF) or bFGF accelerates dermal as well as epidermal proliferation (Pierce et al. 1988; Greenhalgh et al. 1990). When it was reported that KGF mRNA expression was elevated by as much as 160 -fold after skin injury (Werner et al. 1992), KGF was tested in wound assays and shown to stimulate keratinocyte pro- 
liferation and basement membrane maturation dramatically (Staiano-Coico et al. 1993; Pierce et al. 1994). The notion that KGF is essential for wound healing was supported further by studies reporting that mice expressing a truncated form of KGFR, driven by a human epidermal keratin promoter, were impaired in their ability to grow and re-epithelize at wound sites (Werner et al. 1994). Most recently, it was suggested that the suppression of KGF mRNA expression after skin injury of steroidtreated mice is the cause of associated wound-healing defects (Brauchle et al. 1995).

Our data reveal that in contrast to widely held assumptions, KGF is not required for wound healing, even when expression of TGF- $\alpha$ is also ablated. Conversely, despite its remarkable up-regulation in response to injury, TGF- $\alpha$ is not required for wound healing, even in the absence of KGF. Thus, the major paracrine and autocrine growth factors of the epidermis are dispensable for proper growth, even under extreme situations, for example, re-epithelialization in response to injury. These findings lead us to conclude that the processes regulating epidermal proliferation are far more complex than were appreciated previously, and must involve other players. Moreover, our data argue that the woundhealing defects seen in glucocorticoid-treated animals (Brauchle et al. 1995) arise from a mechanism that does not involve KGF mRNA suppression.

Although much less potent, EGF and aFGF can activate EGFR and KGFR, respectively, and, hence, they may assist in orchestrating proliferative control in keratinocytes. EGFR knockout mice have been described recently (Miettinen et al. 1995; Sibilia and Wagner 1995; Threadgill et al. 1995), and the effects on epidermal growth seem to be more pronounced than that in the TGF- $\alpha$ knockouts. This said, the thickness of the skin of EGFR $(-/-)$ mice is altered only modestly, particularly in newborn animals, and at least a part of this can be attributed to the inability of TGF- $\alpha$ to function. Moreover, BrdU labeling suggests that the mitotic activity in skin keratinocytes is still appreciable even in the absence of the EGFR pathway. Thus, whereas there is no doubt that the consequences of ablating the EGFR are more severe than ablating TGF- $\alpha$, these recent findings underscore further the notion that there is significantly more to growth regulation in the epidermis than the EGFR pathway.

Thus far, the role of the KGFR pathway in epidermal growth and in wound healing remains unknown. Whereas the truncated KGFR transgenic studies are suggestive that the KGFR pathway may be required for the wound-healing process (Werner et al. 1994), these results are not unequivocal because (1) the mutant receptor is one that is able to complex with all FGFRs, and (2) there may be effects of the transgene product that go beyond its direct effect on the FGFR pathway. Thus, from these studies alone, although it seems likely that wound healing is dependent on tyrosine kinase receptors, and likely FGFRs, it remains to be elucidated whether such effects are specific to KGFR.

A number of issues remain to be addressed regarding the possible role of KGFR in epidermal growth and wound healing. Knowing that KGFRs are not fully saturated by endogenous ligand levels (Guo et al. 1993), the levels of aFGF would have to be up-regulated dramatically to compensate for the loss of the more potent KGF. Whereas we did not observe a change in the aFGF RNA level of the KGF knockout mice, it is possible that translational regulatory mechanisms, as yet unexplored, may be able to elevate the active levels of aFGF to compensate for the loss of KGF in our animals. Direct testing of this possibility, and more generally of the functions of the KGFR pathway, now awaits the generation of knockout mice that are ablated for the KGF-specific exon of FGFR2.

\section{Materials and methods}

Isolation of genomic DNA from ES cells and from mouse tail

ES cells or mouse tails were incubated for $12 \mathrm{hr}$ at $55^{\circ} \mathrm{C}$ in TE buffer ( $1 \mathrm{~mm}$ EDTA, $10 \mathrm{~mm}$ Tris-Cl at $\mathrm{pH} 8$ ) containing $20 \mathrm{~mm}$ $\mathrm{NaCl}, 1 \% \mathrm{SDS}$, and $1 \mathrm{mg} / \mathrm{ml}$ of proteinase $\mathrm{K}$. Solutions were then extracted with an equal volume of buffer-equilibrated phenol, followed by precipitation of the DNAs with $20 \mathrm{~mm}$ sodium acetate in $95 \%$ ethanol. After $75 \%$ and $95 \%$ ethanol washes, DNAs were resuspended in TE buffer.

\section{Regular and modified PCR}

Regular PCR was conducted as a $50-\mu l$ reaction that contained $1 \mu$ l of DNA template, $5 \mu$ l of $10 \times$ PCR buffer (Perkin-Elmer, Norwalk, CT), $1 \mu \mathrm{l}$ of each primer $(20 \mu \mathrm{M}), 0.25 \mu \mathrm{l}$ of Taq polymerase (Perkin-Elmer), and water. Cycling conditions were 35 cycles of $94^{\circ} \mathrm{C}$ for $1 \mathrm{~min}, 55^{\circ} \mathrm{C}$ for $1 \mathrm{~min}$, and $72^{\circ} \mathrm{C}$ for $1 \mathrm{~min}$.

To generate long PCR fragments to screen for homologous recombination, the "hot start" technique was employed to ensure maximum specificity. PCRs were constituted in PerkinElmer thin-walled reaction tubes containing $1.5 \mu$ l of the primer set, $5 \mu$ l of $25 \mathrm{~mm} \mathrm{MgCl}_{2}$ (25 mM), $5 \mu$ l of dNTPs (2.5 mM each), $2 \mu \mathrm{l}$ of $10 \times$ PCR chelating buffer (Perkin-Elmer, Norwalk, CT), and $5 \mu \mathrm{l}$ of $150 \mathrm{~mm}$ Tris- $\mathrm{Cl}(\mathrm{pH} 8.8)$. Atop this primary mixture was layered Perkin-Elmer Ampliwax Gem 100 (melted and resolidified), and atop this was layered $1 \mu$ l of DNA template and $1 \mu \mathrm{l}$ of $\mathrm{rTth}$ DNA polymerase (Perkin-Elmer) in a solution of 5 $\mu \mathrm{l}$ of $0.1 \%$ gelatin, $3 \mu \mathrm{l}$ of PCR buffer (as above), and $20 \mu \mathrm{l}$ of $\mathrm{dH}_{2} \mathrm{O}$. The tubes were placed in a Perkin-Elmer PCR machine, and the following cycles were run in sequence: (1) $94^{\circ} \mathrm{C}(45 \mathrm{sec})$; $65^{\circ} \mathrm{C}(45 \mathrm{sec}) ; 72^{\circ} \mathrm{C}(2 \mathrm{~min})$ for $10 \mathrm{cycles}$, followed by $(2) 94^{\circ} \mathrm{C}(45$ $\mathrm{sec}) ; 65^{\circ} \mathrm{C}(45 \mathrm{sec}) ; 72^{\circ} \mathrm{C}$ ( 2 min with 10 -sec increments per cycle) for 30 cycles. PCR products are resolved by electrophoresis through $1 \%$ agarose gels and visualized with ethidium bromide. The following primers were used: mKGF5', AAGGGCGACACACTTCTTCTT; Neo5', GAGGCCACTTGTGTAGCG; mKGF3', TTGATGGAGGAGACTAAAGCG; and Neo3', GCCTCTGTTCCACATACACTT.

\section{Southern blot analysis of genomic DNAs from PCR-positive ES clones}

DNAs were digested with $\mathrm{XbaI}$ and resolved on $0.6 \%$ agarose gels. Gels were treated with $0.25 \mathrm{~N} \mathrm{HCl}$ for $15 \mathrm{~min}$, and then with $0.4 \mathrm{~N} \mathrm{NaOH}$ for $20 \mathrm{~min}$. Gels were then neutralized and transferred to a Bio-Rad (Hercules, CA) GT Zeta membrane, which was then hybridized with ${ }^{32} \mathrm{P}$-labeled cDNA probes. Blots were prehybridized for $2 \mathrm{hr}$ at $60^{\circ} \mathrm{C}$ in a solution of $2 \times$ 
SSC, $1 \%$ SDS, $0.5 \%$ nonfat milk, and $0.75 \mathrm{mg} / \mathrm{ml}$ of denatured sonicated salmon sperm (sss) DNA. Hybridizations were then carried out at $60^{\circ} \mathrm{C}$ for at least $12 \mathrm{hr}$ in a solution of $2 \times 10^{6}$ $\mathrm{cpm} / \mathrm{ml}$ of radiolabeled probe corresponding to a $3^{\prime} \mathrm{KpnI}-\mathrm{XbaI}$ genomic fragment, $2 \times$ SSC, $1 \%$ SDS, $0.5 \%$ nonfat milk, 0.5 $\mathrm{mg} / \mathrm{ml}$ of denatured sss DNA, and $10 \%$ dextran sulfate. Blots were washed for $30 \mathrm{~min}$ each, first with $1 \times \mathrm{SSC}, 1 \% \mathrm{SDS}$, and then twice with $0.1 \times \mathrm{SSC}$, and $0.1 \%$ SDS at $60^{\circ} \mathrm{C}$, before being exposed to film. The expected homologous recombination event was confirmed for each clone: 8 -kb band, wild-type KGF allele; 6 -kb band, targeted allele (data not shown). Note: ES clones containing the $5^{\prime}$ and 3 ' mutant-specific bands were obtained at a frequency of $\sim 1: 20$. ES blots (not shown) were rehybridized with a neo probe to verify single integration.

\section{RNase protection assay}

Radiolabeled cRNA riboprobes were fractionated by electrophoresis through a $0.6 \%$ urea/acrylamide gel. After excising the fragments from the gel, probes were then eluted at $50^{\circ} \mathrm{C}$ for $1 \mathrm{hr}$ in $500 \mu \mathrm{l}$ of elution buffer (for $6 \mathrm{ml}: 1 \mathrm{ml}$ of $3 \mathrm{M} \mathrm{NaAc}, 5 \mathrm{ml}$ of DEPC-treated water, $30 \mu \mathrm{l}$ of $0.5 \mathrm{M}$ EDTA). After phenol/chloroform extraction, $\sim 15,000 \mathrm{cpm}$ per probe was used for each hybridization reaction.

Aliquots $(5-40 \mu \mathrm{g}$, depending on the probe) of total RNAs from each sample were hybridized with the cRNA probes. Hybridizations were conducted in $20 \mu$ l of buffer $(1.6 \mathrm{M} \mathrm{NaCl}, 80$ $\mathrm{mM}$ Tris at $\mathrm{pH} 7.0,4 \mathrm{~mm}$ EDTA at $\mathrm{pH} 8.0,0.4 \%$ SDS, diluted $1: 4$ in formamide) at $56^{\circ} \mathrm{C}$ overnight. The reaction mixes were then digested with an RNase solution of $200 \mu \mathrm{l} / 10 \mathrm{mM}$ Tris at $\mathrm{pH}$ $7.5,5 \mathrm{~mm}$ EDTA at $\mathrm{pH} 8.0,0.3 \mathrm{M} \mathrm{NaCl}, 100$ units of RNase Tl, and $7.2 \mu \mathrm{g}$ of RNase A/ at $31^{\circ} \mathrm{C}$ for $50 \mathrm{~min}$. After further precipitation, the resultant protected fragments were resolved by electrophoresis through $6 \%$ denaturing agarose gels, which were subsequently dried and exposed to X-ray film.

\section{Wound-healing experiments}

Freshly shaven backs of wild-type and knockout mice were incised with a scalpel to create full-thickness wounds. Backskin tissues within $2 \mathrm{~mm}$ of each wound were harvested after 1 day. For control unwounded samples, mice were shaven immediately before sacrificing, and equivalent backskin tissues were collected for RNA isolation. In some cases, an alternative method was used. In this case, a small section of tail was amputated from each mouse (Mann et al. 1993). At various times after wounding, additional segments of tail ends were amputated, fixed with $4 \%$ paraformaldehyde overnight, and then embedded in paraffin such that the exposed end of the tail segment could be sectioned and stained with hematoxylin and eosin.

\section{Acknowledgments}

We thank Dr. Jian Cheng for her helpful discussions and guidance in ES cell culture, and Dr. Q-C. Yu for his many hours of electron microscopic analysis. A special thank you goes to Ms. Elizabeth M. Hutton and Dr. Len Milstone for their helpful comments and for their expert assistance on various phases of the hair analyses, to Ms. Hutton for her additional experiments on the reproductive tract of the knockout mice, and to Dr. Milstone for his valuable comments on the manuscript. This work was funded by a grant from the National Institutes of Health. E.F. is a Howard Hughes Medical Institute Investigator.

The publication costs of this article were defrayed in part by payment of page charges. This article must therefore be hereby marked "advertisement" in accordance with 18 USC section 1734 solely to indicate this fact.

\section{References}

Alarid, E.T., J.S. Rubin, P. Young, M. Chedid, D. Ron, S.A. Aaronson, and G.R. Cunha. 1994. Keratinocyte growth factor functions in epithelial induction during seminal vesicle development. Proc. Natl. Acad. Sci. 91: 1074-1078.

Barrandon, Y. and H. Green. 1987. Cell migration is essential for sustained growth of keratinocyte colonies: The roles of transforming growth factor-alpha and epidermal growth factor. Cell 50: 1131-1137.

Brauchle, M., R. Fassler, and S. Werner. 1995. Suppression of keratinocyte growth factor expression by glucorcorticoids in vitro and during wound-healing. I. Invest. Dermatol. 105: 579-584.

Clark, R.A.F. 1985. Cutaneous tissue repair. Basic biologic considerations. I. Am. Acad. Dermatol. 13: 701-710.

Culig, Z., A. Hobixch, M.V. Cronauer, C. Radmayr, J. Trapman, A. Hittmair, G. Bartxch, and H. Klocker. 1994. Androgen receptor activation in prostatic tumor cell lines by indulinlike growth factor-I, keratinocyte growth factor, and epidermal growth factor. Cancer Res. 54: 5474-5478.

Dry, F.W. 1926. The coat of the mouse (Mus musculus). I. Genet. 16: 287-340.

Falconer, D.S. and G.D. Snell. 1953. Two new hair mutants: rough and frizzy. J. Hered. 43: 53-57.

Finch, P.W., J.S. Rubin, T. Miki, D. Ron, and S.A. Aaronson. 1989. Human KGF is FGF-related with properties of a paracrine effector of epithelial cell growth. Science 245: 752755.

Finch, P.W., G.R. Cunha, J.S. Rubin, J. Wong, and D. Ron. 1995. Pattern of keratinocyte growth factor and keratinocyte growth factor receptor expression during mouse fetal development suggests a role in mediating morphogenetic mesenchymal-epithelial interactions. Dev. Dynam. 203: 223-240.

Greenhalgh, D.G., K.H. Sprugel, M.J. Murray, and R. Ross. 1990. PDGF and FGF stimulate wound healing in the genetically diabetic mouse. Am. I. Pathol. 136: 1235-1246.

Guo, L., Q.-C. Yu, and E. Fuchs. 1993. Targeting expression of keratinocyte growth factor to keratinocytes elicits striking changes in epithelial differentiation in transgenic mice. EMBO J. 12: 973-986.

Hebert, J., T. Rosenquist, J. Gotz, and G. Martin. 1994. FGF5 as a regulator of the hair growth cycle: Evidence from targeted and spontaneous mutations. Cell 78: 1017-1025.

Housley, R., C.F. Morris, W. Boyle, B. Ring, R. Biltz, J.E. Tarpley, S. Aukerman, P.L. Devine, R.H. Whitehead, and G.F. Pierce. 1994. Keratinocyte growth factor induces proliferation of hepatocytes and epithelial cells throughout the rat gastrointestinal tract. J. Clin. Invest. 94: 1764-1777.

Johnson, D.E. and L.T. Williams. 1993. Structural and functional diversity in the FGF receptor multigene family. $A d v$. Cancer Res. 60: 1-41.

Kelley, M.J., M. Pech, H. Seuanez, J. Rubin, S. O'Brien, and S.A. Aaronson. 1992. Emergence of the keratinocyte growth factor multigene family during the great ape radiation. Proc. Natl. Acad. Sci. 89: 9287-9291.

Liang, T., S. Hoyer, R. Yu, K. Soltani, A. Lorincz, R.A. Hiipakka, and S. Liao. 1993. Immunocytochemical localization of androgen receptors in human skin using monoclonal antibodies against the androgen receptor. Soc. Invest. Dermatol. 100: $663-666$.

Luetteke, N.C., T.H. Liu, R.L. Peiffer, P. Oliver, O. Smithies, 
and D.C. Lee. 1993. TGF $\alpha$ deficiency results in hair follicle and eye abnormalities in targeted and waved-1 mice. Cell 73: 263-278.

Lyon, M.F. and S.G. Hawkes. 1972. X-linked gene for testicular feminization in the mouse. Nature 227: 1217-1219.

Mann, G.B., K.J. Fowler, A. Babriel, E.C. Nice, R.L. Williams, and A.R. Dunn. 1993. Mice with a null mutation of the TGF $\alpha$ gene have abnormal architecture, wavy, and curly whiskers and often develop corneal inflammation. Cell 73: 249-261.

Mason, I.J., F. Fuller-Pace, R. Smith, and C. Dickson. 1994. FGF-7 (keratinocyte growth factor) expression during mouse development suggests roles in myogenesis, forebrain regionalisation and epithelial-mesenchymal interactions. Mech. Dev. 45: 15-30.

Mattei, M.-G., O. deLapeyriere, J. Bresnick, C. Dickson, D. Birnbaum, and I. Mason. 1995. Mouse FGF7 (fibroblast growth factor 7) and FGF8 (fibroblast growth factor 8) genes map to chromosomes 2 and 19 respectively. Mamm. Genet. 6: 196197.

Miettien, P.J., J.E. Berger, J. Meneses, Y. Phung, R.A. Pedersen, Z. Werb, and R. Derynck. 1995. Epithelial immaturity and multiorgan failure in mice lacking epidermal growth factor receptor. Nature 376: 337-341.

Miki, T., T.P. Fleming, D.P. Bottaro, J.S. Rubin, D. Ron, and S.A. Aaronson. 1991. Expression cDNA cloning of the KGF receptor by creation of a transforming autocrine loop. Science 251: 72-75.

Miki, T., D.P. Bottaro, T.P. Fleming, D.L. Smith, W.H. Burgess, A.M.-L. Chan, and S.A. Aaronson 1992. Determination of ligand-binding specificity by alternative splicing: Two distinct growth factor receptors encoded by a single gene. Proc. Natl. Acad. Sci. 89: 246-250.

Mohn, M.P. 1958. The effects of different hormonal states on the growth of hair in rats. In The biology of hair growth (ed. William Montagna and Richard Ellis), pp. 335-398. Academic Press, New York, NY.

Panos, R.S., J.S. Rubin, S.A. Aaronson, and R.J. Mason. 1993. Keratinocyte growth factor and hepatocyte growth factor/ scatter factor are heparin-binding growth factors for alveolar type II cells and fibroblast-conditioned medium. J. Clin. Invest. 92: 969-977.

Pierce, G.F., T.A. Mustoe, R.M. Senior, J. Reed, G.L. Griffin, A. Thomason, and T.F. Deuel. 1988. In vivo incisional wound healing augmented by platelet-derived growth factor and recombinant c-sis gene homodimeric proteins. J. Exp. Med. 167: 974-987.

Pierce, G.F., J.E. Tarpley, R.M. Allman, P.S. Goode, C.M. Serdar, B. Morris, T.A. Mustoe, and J. Vande Berg. 1994. Tissue repair processes in healing chronic pressure ulcers treated with recombinant platelet-derived growth factor BB. Am. I. Pathol. 145: 1399-1410.

Rappolee, D.A., D. Mark, M.J. Banda, and Z. Werb. 1988. Wound macrophage express TGF- $\alpha$ and other growth factors in vivo: Analysis by mRNA phenotyping. Science 241: 708-712.

Rheinwald, J.G. and H. Green. 1975. Serial cultivation of strains of human epidermal keratinocytes: The formation of keratinizing colonies from single cells. Cell 6: 331-343.

Ron, D., D.P. Bottaro, P.W. Finch, D. Morris, J.S. Rubin, and S.A. Aaronson. 1993. Expression of biologically active recombinant keratinocyte growth factor. I. Biol. Chem. 268: 2984-2988.

Rosenquist, T.A. and G.R. Martin. 1996. FGF signalling in the hair growth cycle: Expression of the FGF receptor and ligand genes in the murine hair follicle. Dev. Dynam. 205: (in press).
Rubin, J.S., H. Osada, P.W. Finch, W.G. Taylor, S. Rudikoff, and S.A. Aaronson. 1989. Purification and characterization of a newly identified growth factor specific for epithelial cells. Proc. Natl. Acad. Sci. 86: 802-806.

Schultz, G.S., M. White, R. Mitchell, G. Brown, J. Lynch, D.R. Twardzik, and G.J. Todaro. 1987. Epithelial wound healing enhanced by transforming growth factor- $\alpha$ and vaccinia growth factor. Science 235: 350-352.

Sibilia, M. and E. Wagner. 1995. Strain-dependent epithelial defects in mice lacking the EGF receptor. 1995. Science 269: 234-238.

Siracusa, L.D. and C.M. Abbott. 1994. Chromosome 2. Mamm. Genet. 5: S22-S39.

Staiano-Coico, L., J.G. Krueger, J.S. Rubin, S. D'limi, V.P. Vallat, L. Valentino, T. Fahey III, G. Hawes, G. Kingston, M.R. Madden, M. Mathwich, A.B. Gottlieb, and S.A. Aaronson. 1993. Human keratinocyte growth factor effects in a porcine model of epidermal wound healing. $J$. Exp. Med. 178: 865878.

Threadgill, D.W., A.A. Dlugosz, L.A. Hansen, T. Tennenbaum, U. Lichti, D. Yee, C. LaMantia, T. Mourton, K. Herrup, R.C. Harris, J.A. Barnard, S.H. Yuspa, R.J. Coffey, and T. Magnuson. 1995. Targeted disruption of mouse EGF receptor: Effect of genetic background on mutant phenotype. Science 269: 230-234.

Ulich, T., E.S. Yi, K. Longmuir, S. Yin, R. Blitz, C.F. Morris, R.M. Housley, and G.F. Pierce. 1994. Keratinocyte growth factor is a growth factor for type II pneumocytes in vivo. $J$. Clin. Invest. 93: 1298-1306.

Vassar, R. and E. Fuchs. 1991. Transgenic mice provide new insights into the role of TGF- $\alpha$ during epidermal development and differentiation. Genes \& Dev. 5: 714-727.

Werner, S., K.G. Peters, M.T. Longaker, F. Fuller-Pace, M.J. Banda, and L.T. Williams. 1992. Large induction of keratinocyte growth factor expression in the dermis during wound healing. Proc. Natl. Acad. Sci. 89: 6896-6900.

Werner, S., H. Smola, X. Liao, M.T. Longaker, T. Krieg, P.H. Hofschneider, and L.T. Williams. 1994. The function of KGF in morphogenesis of epithelium and reepithelialization of wounds. Science 266: 819-822.

Yan, G., Y. Fukabori, S. Nikolaropoulos, F. Wang, and W.L. McKeehan. 1992. Heparin-binding keratinocyte growth factor is a candidate stromal to epithelial cell andromedin. Mol. Endocrinol. 6: 2123-2128.

Yi, E.S., S. Yin, D.L. Harclerode, A. Bedoya, N.B. Bikhazi, R. Housley, S.L. Aukerman, C.F. Morris, G.F. Pierce, and T.R. Ulich. 1994. Keratinocyte growth factor induces pancreatic ductal epithelial proliferation. Am. I. Pathol. 145: 80-85. 


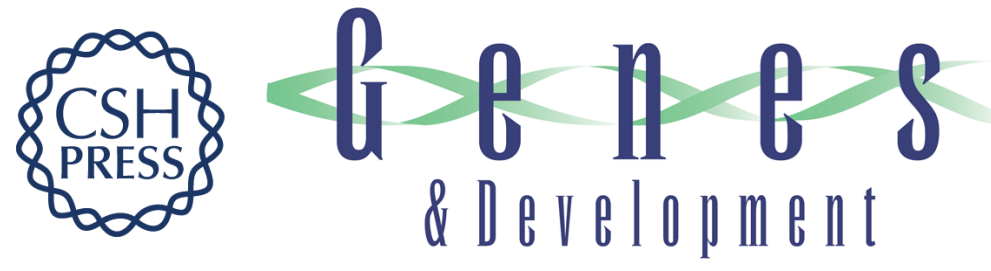

\section{Keratinocyte growth factor is required for hair development but not for wound healing.}

L Guo, L Degenstein and E Fuchs

Genes Dev. 1996, 10:

Access the most recent version at doi:10.1101/gad.10.2.165

References This article cites 42 articles, 17 of which can be accessed free at: http://genesdev.cshlp.org/content/10/2/165.full.html\#ref-list-1

License

Email Alerting

Service

Receive free email alerts when new articles cite this article - sign up in the box at the top right corner of the article or click here.

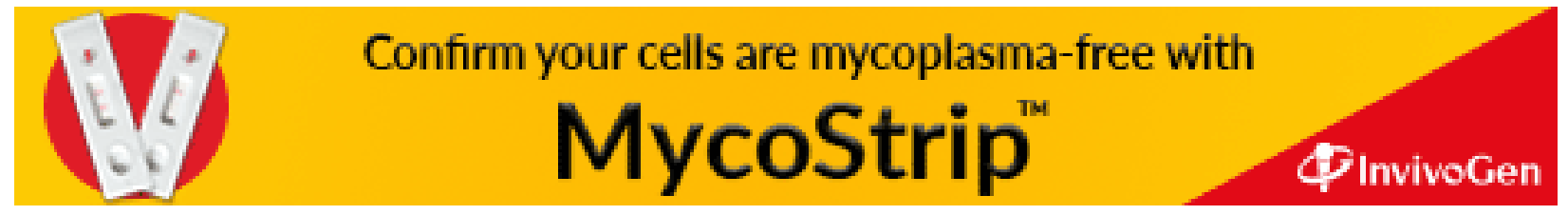

